\title{
The "Dominos" that Need to Fall into Place for a Reunification of Korea: Making Sense of a United Korea
}

\author{
Michael Harvey, Timothy Kiessling \& Miriam Moeller
}

To cite this article: Michael Harvey , Timothy Kiessling \& Miriam Moeller (2013) The "Dominos" that Need to Fall into Place for a Reunification of Korea: Making Sense of a United Korea, Journal of East-West Business, 19:3, 181-198, DOI: 10.1080/10669868.2013.787957

To link to this article: https://doi.org/10.1080/10669868.2013.787957

Published online: 06 Aug 2013.

Submit your article to this journal ¿

Џ Article views: 335 


\title{
The "Dominos" that Need to Fall into Place for a Reunification of Korea: Making Sense of a United Korea
}

\author{
MICHAEL HARVEY \\ Department of Management, School of Business Administration, University of Mississippi, \\ University, Mississippi, USA, and International Business, Bond University, Gold Coast, \\ Queensland, Australia \\ TIMOTHY KIESSLING \\ Department of Management, Bilkent University, Ankara, Turkey \\ MIRIAM MOELLER \\ Faculty of Business, Economics and Law, University of Queensland, Queensland, Australia
}

\begin{abstract}
With the death of North Korea leader Kim Jong-il, the level of uncertainty will dramatically escalate in an already bighly uncertain market. The question becomes, is there a market opportunity for Western organizations, and when should Western organizations attempt to enter North Korea? In addition, there is a large question looming over the potential changes in the country, that being, if and when reunification with South Korea will occur. This article examines the potential of a unified market on the Korean peninsula.
\end{abstract}

KEYWORDS absence of data, emerging market, future economic potential, Korea, market entry strategies, reunification

On December 19, 2011, the aging leader of North Korea, Kim Jong-il, died of a heart attack at the age of 69, ending the personality cult that had gripped North Korea for the last 17 years. The aftermath of his 17-year heavy-handed dictatorship is unclear, but Kim's youngest son, Kim Jong-un, became the next leader of the secretive communist state of North Korea. The outcome

Received February 14, 2013; revised March 11, 2013; accepted March 11, 2013.

Address correspondence to Michael Harvey, University of Mississippi, 320 Holman Hall, Department of Management, School of Business Administration, University, MS 39677-1848, USA. E-mail: mharvey@bus.olemiss.edu 
of this change in leadership in North Korea is a source of speculation throughout the world but nowhere more closely anticipated than in South Korea. What will the future be for these two countries: to unify or not?

\section{INTRODUCTION}

In October of 2010, a coalition of German and South Korean policymakers assembled to seriously examine how the model of Germany's 1990 unification movement might be applied to the Koreas today (Homola 2010). Although foreign policy authorities disagree on the likeliness of a complete, Germany-style unification of the cousin states within the next 10 years, normalized trade relations between the two within the next 5 years seems probable ("One Korea?" 2008). The complete unification of the Republic of Korea and strategic potential due to the death of Kim Jong-il opens the door for movement toward Korean unification in the coming years; these steps signal the potential for a considerable, if only a hypothetical, future emerging market. How to assess the potential of entering this emerging market is another concern entirely.

Experts have theorized that the most trusted investors in a financially open North Korea, in this light, would be Japan, China, and South Korea (Conforti 1999). Therefore, the promise of this potentially emerging market after unification would have to be tied to fiscal and/or politically united Korea. Despite the obstacles, Westerners have already begun to bridge the Korea "gap" by establishing significant trade and export efforts toward South Korea and China. Successes in China are clearly widespread; however, North Korea, too, is already recognized as a promising yet sometimes overlooked emerging market for foreign investment, boasting strong growth, high value, and equally high risk (Dawson 2005). If the existing relationships in neighboring Asian nations continue to strengthen, it is forecast that in 5 to 10 years, Americans will be ready and willing to enter North Korea through limited strategic efforts (e.g., strategic alliances with other Asian countries; Hwang 2010; Kerr 2005; Rosecrance 2006). Thus, American organizations could embrace the economically deprived market in North Korean and at the same time the United States could take competitive advantage of the labor, land, and resources available in the previously under-developed economic platform. The strategy could ultimately be worth the risk involved; even if a unified Korea would at first seem fiscally and politically unstable, as did the united Germany of 1990, and the Germans today have overcome many obstacles and achieved significant economic success (Hart-Landsberg 1996).

Indeed, Korea's recent development in many ways mirrors a democraticization of China's development in the years after its reformation and opening up to the global marketplace, making the economically unified Koreas an attractive and very plausible market for some consumer goods. However, as many American companies have already discovered, working with 
the established cultural and government barriers in place in many Asian economies is no small task (Worden 2008). North Korea presents an especially difficult case to consider, since, for all practical purposes, the nation remains and will more than likely remain closed to the Western World for a number of years after the projected unification (Hwang 2010; Mitchell 2002; Shambaugh 2003).

In order to enter a unified Korean market with any chance of success, it has been suggested that interested American firms start early by establishing stronger bases in China and South Korea in order to catch the opportunities before it unification occurs (Mitchell 2002; Stares and Wit 2009). This may be a very difficult strategy to implement given the present unstable economic conditions in the United States as well as the rest of the world. By comparing Korea's unification to its only precedent, the existing German example, and to the economies of other Asian nations, along with a brief examination of the successes and strategies of Asian companies such as China's Hai'er (Duysters 2009), it is the intent of this article to outline a market-entry strategy that would occur given a reunification of North and South Korea economically and/or politically. The fact of the matter is that U.S. companies as well as the government would need to act quickly and preemptively in order to be a viable competitor in a new, unified Korean economy. In addition, the level of commitment to South Korea over the last 50 years requires the United States to play an integral role in unification if that is the direction that evolves out of this change in leadership.

\section{NORTH KOREA: A CLIMATIC ASSESSMENT OF ITS FUTURE}

Because North Korea is still an economy "closed" to the United States, factual economic data and reliable information regarding the nation's infrastructure, development, and culture are difficult to come-by. What we know about North Korea's economic (Worden 2008), cultural (Chamberlin 2004), and political environment (Hwang 2010) is drawn from the culturally similar South Korea, data from friendly nations with trade relations in North Korea, and intelligence gathered through the Central Intelligence Agency. Laying out the specific attributes of North Korea as compared to its far more modernized "sister state" to the South can provide potential market entrants a crisper view of the specific problems business in the unified Koreas might face in the future. An understanding of the current North Korean economic situation, as compared to other countries in the region, will also aid the formulation of market entry strategy.

\section{Political and Economic Environment in North Korea}

Concerning North Korea's political structure, the nation is considered a socialist developing country, with a basic market structure similar to the 
economic makeup systems of Vietnam and Cuba (Ducruet and Cheol 2008). A comparatively low per-capita gross domestic product (GDP) and heavy economic control through a tightly centralized government in Pyongyang has resulted in an agrarian populace (estimated to be up to $80 \%$ of the population) susceptible to famine and drought (Central Intelligence Agency 2013; Noland, Robinson, and Wang 2000). To outside observers, it would not be readily apparent that the population in North Korea of poor peasant farmers seems to lack purchasing power to acquire consumer goods. Indeed, the standard of living in North Korea is drastically below that of South Korea, and per-capita GDP is a mere one-seventeenth of South Korea's (see Pinkston and Saunders 2003). Improvement to North Korea's standard of living is dependent upon attracting foreign investment from China, Russi,a and other major trading partners (Kerr 2005). Open trade relations could also indirectly improve having a very positive impact on the average citizen's standard-of-living (Mitchell 2002; Shambaugh 2003).

At first glance, North Korea at present or in the future would seem to be the least likely venue for foreign trade. Tight government regulation, political and economic sanctions, and a dismally poor populace all seem insurmountable barriers to foreign investment and entry into the pre-emerging South Korean market. However, compared to other nations with similar economic structures, such as Vietnam and Cuba, North Korea enjoys certain advantages. According to the Transport Reviews scholarly journal, North Korea has a "particular advantage" over other similarly structured political economies. North Korea's strategic location, close to the enormous, major markets in China, South Korea, Japan, and Russia, as well as its access to the Sea of Japan and Pacific Ocean (Central Intelligence Agency 2013; Noland et al. 2000; Smith 2002) all provide a favorable environment for increased trade. These advantages, however, are not utilized to their full potential in the current North Korean trade structure. Based on somewhat tenuous data, it appears that China and South Korea presently dominate trade in North Korea (figure 1).

Both China and South Korea have positive trade relations with the United States. Although China remains a nominally socialist country and both ideologically and structurally retains certain similarities with North Korea, plentiful trade relationships exist between China and the United States (Rosecrance 2006; Shambaugh 2003; Smith 2002). South Korea is an economically successful, functioning democracy with close trade ties to the United States. In preparation for any sort of future economic unification of the Korean states, it seems one way for a strategic oriented company to enter an economically open North Korea would be to establish subsidiaries in South Korea and China. Doing so would enable American personnel to gain vital experience and insight into the Korean culture and climate as well as work on forming trusting relationships with important Chinese and Korean firms and businesspeople. 


\section{North Korean Import/Export Partners}

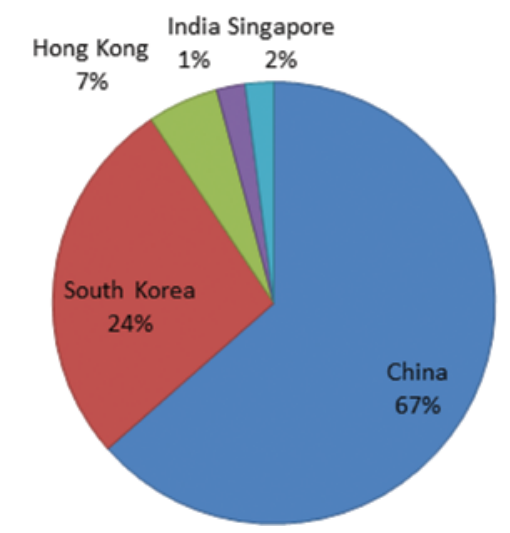

FIGURE 1 Key trading partners of North Korea. Source: Central Intelligence Agency (2013) (color figure available online).

\section{The Potential of Economic Integration of North and South Korea}

Many would argue that the current political-economic structure of North Korea is anathema to substantial foreign trade. South Korea, on the other hand, has decidedly established itself on a global scale as an exporter with high economic growth and purchasing power parity. Combining the two culturally similar yet politically different nations may result in chaos and disunity at first, but eventually the combined economies would fuse into an emerging market with a population twice the size of the South Korean predecessor (Moltz 2004; Stares and Wit 2009; Stein 2002). Even more likely, since the South Korean government would prefer that gradual economic integration precede political unification, the two nations hypothetically may remain separate political entities yet merge their two lopsided economies into a notvery-appealing, yet still approachable, trade market ("One Korea?" 2008; Young, Lee, and Zang 2000).

In any case, given the immense cultural, political, and economic barriers in place barring trade between the existing North Korea and the United States, one can only surmise what would happen if the United States would decide to lift its trade sanctions on a friendlier, unified Korea (Carpenter and Bandow 2004; Dawson 2005; Hwang 2010). Foreign business interest ensconced in the rapidly developing South Korean market has enabled the Asian nation to witness nearly unprecedented economic growth, and it appears that there is a strong correlation between foreign investment and the rapid growth already seen in China, Japan, and South Korea. This investment would have to be applied to North Korea in order to encourage the same sort of rapid growth present in South Korea. In fact, several experts in the field of international economics have even theorized that the foreign 
private sector may play a role in facilitating and strengthening Korean economic unification (Hwang 2010; Young et al. 2000).

Investigating what forces might encourage the Koreas in the foreseeable future either economically or politically has been fitting subject matter for hundreds of different articles since the Korean War. Such foreign policy subject matter is outside the scope of this article's emerging market analysis. For the purposes of this study, let us assume that North Korea, for whatever reasons, has decided to open trade relations with the United States, that the United States has removed its sanctions on North Korea, and that North Korea has joined with the stronger democracy of South Korea. If these various requisites are in place, entrance into one united Korean emerging market with one common Korean culture is possible for American companies (Carpenter and Bandow 2004). However, such entry will be difficult and time-consuming and ideally would entail certain measures of preemptive action.

\section{Framework for Market Entry in Centrally Controlled Markets}

Based on the data previously discussed, North Korea alone seems to present even greater barriers to Western trade than might be expected. A successful market entry strategy into North Korea, therefore, is difficult to formulate presently, mainly because there seems to be no market in North Korea for most of the countries in the world. A good market entry strategy for united Koreas is even more difficult to propose, mainly because there is little to no established precedent for the economic but not political unification of Asian states.

However, based on an analysis of some of the information previously discussed, certain facts seem to stand out: (1) Even though political ideologies may differ, North Korea and South Korea share essentially the same cultural values and beliefs (Mitchell 2002); (2) China, South Korea, and certain other friendly nations have already successfully entered the North Korean market and engaged in considerable trade (Shambaugh 2003); and (3) under the present system, North Korean trade environment would appear unfavorable, even to the most intrepid globalization advocate. Nonetheless, trade between even the most seemingly unfriendly nations is still possible; as the trade graph shows, North and South Korea are reasonably civil trading partners (Rosecrance 2006). What this means is that firms established in South Korea, whether domestic or foreign, might have a greater chance of breaking into a chaotic, open North Korean emerging market same form of unification occur. Because of cultural similarities, similar entry strategies can be applied to both Koreas under a united economy. Also, at the same level, the Koreas do wish to present a united front to the rest of the world for business purposes, much as "unification" of sorts has already occurred in the European Union and in the "unification" of the many diverse provinces of China. 
In the eyes of foreign organizations (American companies in particular), North Korea is in a position not too far removed from the world's most promising developing economy. Regardless, hypothetically combining the two Koreas possess certain aspects making them stand out as an emerging market. North Korea's population, if allowed the economic liberty associated with economic unification with South Korea, would elevate the combined Koreas into the next great emerging economy. A country with an estimated population of 24,457,492 (Kerr 2005; Mitchell 2002), North Korea is the 48th most populous country in the world. Add that more than 24 million to South Korea's population of 48,754,657 (South Korea 2011), and the combined Koreas generate a consuming population of roughly 73 million people. Given the small size of the Korean Peninsula, this teeming unified population would provide a plentiful labor market, one vital component to growth in emerging markets. Still, in order to pique the interests of foreign investors, the population in an emerging economy needs to be able to purchase goods and services. A large labor supply would quickly fill jobs and begin to earn income, and subsequent demand for products would presumably follow. Population is an important driver in emerging economies.

It is the population of this region and its potential purchasing power that could pique the interest of those companies wishing to do business in economically combined Koreas. Market entrants into an economically unified Korea would need to market products targeting specific sectors of the population and would need to take into consideration the overall population's level of purchasing power. North and South Korea at present are essentially dissimilar economic markets, whose consumers would have dramatically different demands (Carpenter and Bandow 2004; Central Intelligence Agency 2013). A North-South Korean "hybrid" market would also entail a peculiar warping of the present GDP per capita in each Korea (Nolan et al. 2000).

The purchasing power of various economically and geographically influential nations, including North Korea, much of Asia, and the United States, is presented in figure 2 .

Figure 2 presents a comparison of the gross domestic product (GDP) per capita in a variety of Asian nations, along with that of the United States. GDP per capita represents the consumer purchasing power, on average, of the citizens of a country. Based on this graph, it is apparent that North Korea's GDP per capita falls harshly below that of South Korea, Thailand, and even Vietnam, a Southeast Asian nation with a vaguely similar market structure. While North Korea's per capita GDP may seem to be lagging unusually far behind compared to that of other rapidly growing Asian countries, there is still hope for consumer demand under a united economic system.

In fact, even at present, North Koreans still enjoy a noticeably higher GDP per capita than people from Bangladesh ( $\$ 1,700$ per capita) and incredibly higher than those of the subsistence-farming people in Zimbabwe $(\$ 400$ 


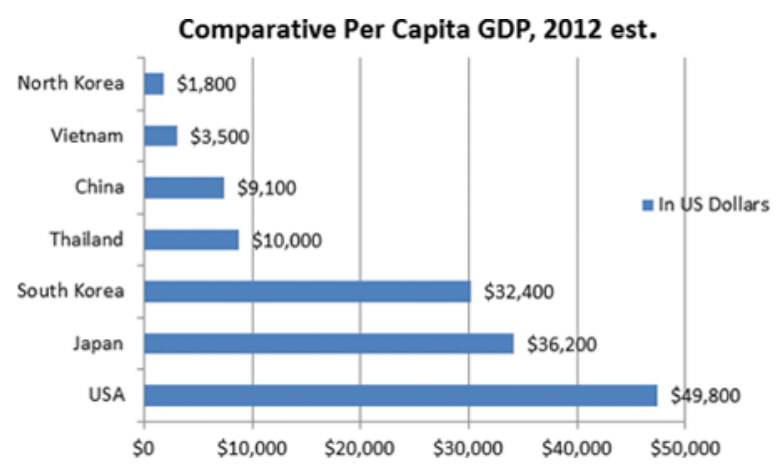

FIGURE 2 Per capital income for comparison purposes. Country comparisons: GDP - per capita (purchasing power parity). Source: Central Intelligence Agency (2013) (color figure available online).

per capita) or Burundi ( $\$ 300$ per capita; Arrighi, Silver, and Brewer 2003; Central Intelligence Agency 2013). While a relatively low GDP per capita may limit the variety of goods North Koreans would be interested in purchasing, North Koreans would still share the same desire to improve their quality of life and escape abject poverty. With their current level of income, any extra income not spent on (Haggard 2007) medical care could, perhaps, purchase standardized and/or no-frills goods marketed by foreign companies.

A similar set of circumstance could be found in Vietnam after the military struggle that took place in that country (Napier and Nguyen 2005; Nguyen and Napier 2000). Consumers were deprived of consumer goods for nearly a decade. When the armed conflict concluded, the Vietnamese people had pent-up demand and a rapidly growing per-capita income that could be directed at increasing household expenditures (Napier 2005, 2006; Ralston, Nguyen, and Napier 1999; Vu and Napier 2000a, 2000b, 2000c). Whereas the North Korean population lacks the economic wherewithal to expand consumer demand if reunification were to take place, the only caveat that could rectify the lack of purchasing power is the infusion of capital by South Korea family/friends to their northern counterparts. This inward flow of money may provide the foundation for many North Koreas to restart the economic activities. This was not the case in Vietnam in that both elements of the population were deprived of the mechanism to earn money during the war.

Returning to the comparative per capita GDP graph, an additional point of interest is that South Korea's GDP per capita is 17 times greater than that of North Korea. The purchasing power disparity between North and South Korea may seem somehow insurmountable; however, combining the two countries would combine two different GDPs (similar to the reunification that took place in Germany), and wealth would eventually, hopefully, be dispersed equally between the two. While any sort of real averaging of the two economies would take decades, a rudimentary average would place the GDP 
per capita of combined Koreas at approximately $\$ 16,000$ per capita-well over the \$11,200 per capita (Central Intelligence Agency 2013) world average GDP per capita. In an ideal future for the Koreas, GDP per capita in several decades would be well above this average, since job availability for the North Koreans will allow per capita income in the North to increase on a multifold basis, and South Koreans will continue to pursue economic development. What this means is that, in the long run, economically combined Koreas have the eventual potential to become one emerging economic powerhouse. However, thriving or not, the combined Korean emerging market still would present particular hindrance to successful entry on the part of Western companies, especially in the realm of remaining cultural dissimilarities.

\section{Barriers to Market Entry: Cultural Challenges}

Outside of the aforementioned policies and ideological factors barring successful trade between the United States and North Korea, language barriers are also a major deterrent to business even in the friendly emerging market of South Korea. According to some theorists, language barriers caused by faulty translation or incorrect interpretation may cause Americans to misunderstand certain messages or fail to pick-up on vital linguistic nuances (Central Intelligence Agency 2013). These misunderstandings can occur in policy dealings and business alike. Companies wishing to do business in the Koreas, be it North, South, or some sort of unification of the two, must take some sort of measures to avoid misunderstandings in a culturally and linguistically dissimilar environment. Three possible methods of countering this form of misinterpretation are to (1) enforce language learning and culture acclimatization programs among all Western employees prior to any overseas departure; (2) more realistically, hire excellent translators to interpret all business proceedings; or (3) engage in joint ventures and strategic alliances with Korean companies (Duysters 2009; Moltz 2004).

Learning the language of the host country is one of the primary ways to encourage trust between dissimilar cultures (Chamberlin 2004). A wise move for companies currently in some form of business partnership with South Korea would be to encourage Western employees to learn at least a rudimentary level of Korean language. Doing so would illustrate a desire to embrace a dramatically different culture and might gain the business some degree of respect in the eyes of Koreans. With language-learning measures in place, Western organizations with already established investment in South Korea could have a strategic competitive advantage in doing business during a potentially chaotic period during economic unification. Organizations that already have firmly established programs of language and cultural learning and an entrepreneurial corporate culture could gain more trust more quickly from previously closed-off North Korean organizations. Also, a combination of educating Western employees with employing culturally attuned 
translators and entering into joint relationships could help bridge the language and culture gap and make certain companies utilizing such measures comparatively more attractive than others.

Another possible way to work around cultural differences between Western and Korean businesspeople would be to employ the help of third-party representatives, ideally from a neighboring, friendly country with a reasonable degree of cultural similarity. A reasonable choice for a third-party associate to help with work in North Korea would be a Chinese individual with some knowledge of the Korean language, since certain aspects of Korean culture are not terribly different from those of the Chinese (Chamberlin 2004). Because of shared roots in Taoism and Buddhism, as well as an emphasis on Confucian thought, the Koreans and Chinese might see each other as neutral associates who do not appear too "foreign." Chinese associates, if trustworthy, would be a fitting choice because Americans and North and South Koreans all share workably healthy relationships with the Chinese.

On the other hand, a less than ideal choice for a third-party associate would be a Japanese representative. Although Japan and Korea are geographically close and a considerable amount of business interaction takes place between the two nations, the Koreans and Japanese share a tumultuous historical background of exploitation, violence, and distrust, and Japanese cars are nearly impossible to find anywhere in South Korea presently. Employing a Japanese associate would instantly alienate many traditionoriented Korean businesspeople, who might distrust the foreign Westerners because of ingrained prejudice against the "untrustworthy" Japanese. An imperfect alliance may be just enough to scare unified Korean businesspeople away from foreign investment and would be just one more factor working in the favor of domestic firms. Careful attention to cultural nuances and existing bias is necessary to success in any foreign market but particularly in the ritualistic realm of East Asia (Chamberlin 2004; Laney 2003; Park 2002).

\section{Joint Ventures: China's Haier as a Case Study}

Joint venture in research or production has remained a hotly discussed method of market entry in emerging markets. A few American firms have already sought to form production or research partnerships of varying degrees worldwide, to differing degrees of success. However, American firms have not paid much attention to Asian attempts at globalization through joint venture. The Chinese have successfully entered Korea through forms of joint venture, and their example may prove the sort of partnership most trusted and cherished in Asian thought. By allowing Korean experts into an American company's inner circle, listening to those experts' advice, and allying one's company with South Korean companies in such a way as to share risk and jointly invest in an endeavor illustrates a high degree of mutual trust 
and acceptance. Doing so would mimic attempts by Chinese organizations and would also cement existing relationships between Western and Korean firms, thus giving the Western allied firm a head start upon the onset of eventual economic unification of the Koreas.

One precedent example of joint business with local firms in tightly controlled economic environments exists in China's Haier Group. Although Chinese-made household products have traditionally been disregarded internationally on the basis of poor quality, Haier, under new management (Duysters 2009) made a point to pursue a policy of conforming to established international quality standards. Because of policy change, many nations began to seek joint venture opportunities with Haier, leading to increased prestige on the world stage, especially in less developed countries (LDCs). Some of these LDCs that have pursued joint production ventures with Haier include the Philippines, Dubai, Iran, Algeria, Jordan, Pakistan, and Bangladesh (Duysters 2009). Remember that the GDP per capita in Bangladesh $(\$ 1,700)$ is similar to that of North Korea at present $(\$ 1,800)$. Haier has also established shared research operations with many moredeveloped countries, including Germany and South Korea.

This Haier case study is important to an examination of the Korean emerging market because it neatly provides a precedent example of how Asian firms would choose to go about business in Korea and shows a way that American firms could mimic in order to enter the unified Korean market. Not only would joint ventures with Korean partners enable American firms to bypass certain linguistic and cultural barriers to business, but such ventures would also forge trust with the Koreans and make foreign organizations ever so much more likely to succeed in a hostile business environment.

\section{Strategic Assessment to Effectively Compete in a Unified Korean Market}

If unification of South and North Korea were to occur, Western organizations would need to assess their capabilities relative to the new opportunities presented by the consolidated market. The key elements in making such an assessment are outlined in figure 3. Each of these stages of preparedness will be discussed.

\section{SOCIAL/ECONOMIC COMPARISON BETWEEN NORTH/SOUTH KOREAS (VITAL DEMOGRAPHICS)}

The foundation for effectively harvesting the unified Korean market is to gain a clear and/or up-to-date factual insight into the consolidated market. The problem with strategic background vital statistics is that very few (being generous) data have been collected on the population in North Korea for over 25 years. The government statistics are highly suspect, and the data collection 


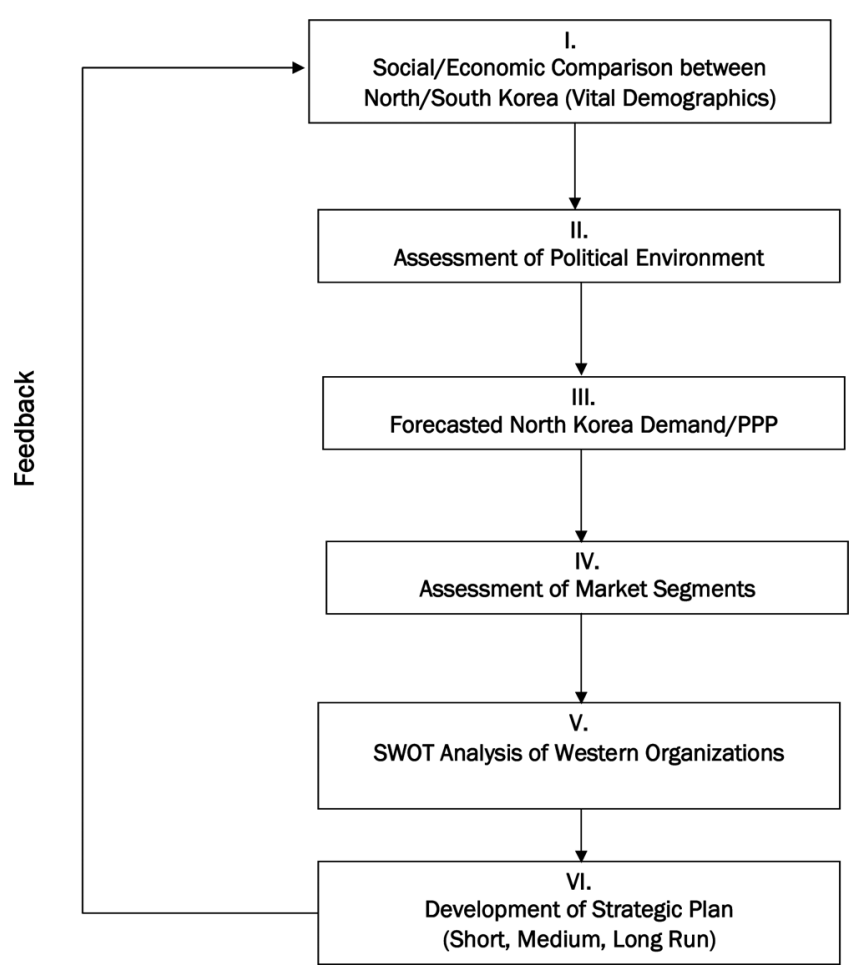

FIGURE 3 Surviving/prospering in a unified Korea environment. Note. PPP: purchasing power parity; SWOT: strengths, weaknesses, opportunities, and threats.

infrastructure to gain data on the populous is nearly nonexistent. Therefore, an external source of information will need to be solicited, more than likely from a Chinese source or in some rare situations from the Russians. That statement should illustrate how desperate Western organizations will be, turning to China/Russia for accurate information! This input could then be triangulated with reports from the U.S. CIA, the United Nations, and Oxfam and other non-government organizations (NGOs). However, Western managers will still have to develop a limited list of data that are needed and some means for rationalizing the value of the information for making investment/ marketing decisions. The key to this stage of the decision process is to limit that data to make decisions on and to collect information from a variety of sources: the management of the organization gaining confidence in the data being collected.

\section{ASSESSMENT OF THE POLITICAL ENVIRONMENT}

If unification were to occur on the Korean peninsula, the resulting government would not resemble the one in Pyongyang or, for that matter, the one in Seoul. The resulting hybrid would have components of both the North 
and South and elements that are contingent on the negotiations of reunification of the two countries (Laney 2003). The assumption would be that the South would have more "say-so" in the reconfiguration of the new government entity, but this may not be the case. The rationale for that statement would center on the 25 years of truculent political behavior of the North on the world stage. It would behoove Western organizations to examine the reunification of Germany to gain a clearer picture of what might happen in the Korean reunification process (Hart-Landsberg 1996; Homola 2010).

The temporal issue is critical to the question of what the government will be like once reunification were to take place. There would be a great deal of behind the "bamboo wall" influence peddling transpiring, where China will attempt to influence the "twenty-something" Kim Jong-un while at the same time Park Geun-hye (South Korean president) will attempt to negotiate with the very young Kim Jong-un. What will transpire is anyone's guess, but it should not assume that the North will have a significantly weaker negotiating stance even given the delicate transition position of the new leadership. President Lee has held a summit with China's president, Hu Jintao, in Beijing focused on different means to develop a strategic partnership between the two Koreas... so the process is already underway. The main goal of the present pre-reunification may be as simple as restraining the new leadership in the North and to build toward stability (Laney 2003). Some form of provocation by the North is within the realm of possibilities given the lack of experience and knowledge of the young leader.

FORECASTING NORTH KOREA'S DEMAND AS WELL AS PERSONAL PURCHASING POWER

While the first stage of this assessment process focused on a social/economic comparison between North and South Korea, this stage of the process needs to develop a forecasting method that will capture the present as well as future purchasing power of the North Korean population (as well as key market segments). The disposal personal income is the foundation of the analysis, but it is important to recognize that other key purchasing power indicators must also be analyzed (e.g., expenditures for food, housing, transportation, education, and discretionary income). While identifying key elements to be monitored, the key consideration would be to develop a reasonable frame of reference to gauge the rate of growth and "critical mass" of indicators needed to make Western entry feasible. This is a similar problem facing organizations attempting to "crack" the base of the pyramid in the global marketplace (Prahalad 2005).

\section{ASSESSMENT OF KEY MARKET SEGMENTS}

Developing a set of "comparative" market segments would entail identification of potential market segments in the reunified Korea and then 
developing a "comparative" frame of reference that can be used assess the market potential of each segment. When combining both the North and South market segments, an "average" market segment must be constructed to make a comparison to the unified segments in Korea (Levin and Han 2003). This "hypothetical" frame of reference could be based on emerging markets, other reunified markets, or some combination of the two. This approach would subjugate the assessors' point of reference (e.g., their own market or their preconceived notions about the reunified Korea market) and provide them with a stable set of segments to compare longitudinally (Mitchell 2002; Smith 2002).

STRENGTHS, WEAKNESSES, OPPORTUNITIES, AND THREATS ANALYSIS OF THE WESTERN ORGANIZATION

What will it take to be successful in the reunified Korean market? Are the requirements for success the same as or similar to other Asian markets? How much time will have to pass after unification for the market to resemble a normal/typical, unified market in Asia? These are crucial questions to be answered by the management of the company attempting to enter the reunified Korean market. A relative competitive advantage will need to be determined prior to entering the market and, if one is not readily apparent, then it should signal the management of the Western organization that the risk associated with entering the market may be too great. In addition, a short-, medium-, and long-term orientation to the development of marketing product/service capabilities needs to be developed to be utilized by the management/marketing managers in the organization.

\section{DEVELOPMENT OF A STRATEGIC PLAN FOR KOREA}

Planning in the face of uncertainty and ambiguous data is a daunting task but one that is critical for Western firms wanting to enter a unified Korea. The expressed policies that are to be accomplish need to be articulated and quantified the best they can (given the limited availability of data on the combined markets). The most difficult issue at this stage of the planning process is to gain confidence in the data and to find repositories of data that instill a trust level in the data as well as the plan for entering Korea that management can make the necessary commitments to the future of doing business in Korea.

The second stage of developing a strategic plan is to articulate the strategies that will be used to reach the explicit business goals for the Korea market. Many of these strategic decisions will be based upon the organizations perceived willingness/need to form strategic alliances on the Korea peninsula. In addition, the recognition that market segments between North and South will remain bifurcate and remain that way for some time, necessitating 
a dual marketing strategy and the concomitant expenses of implementing two strategies.

The third stage of the business plan should focus on the cost, personnel, and time to effectively implement the second stage of the plan. These tactical decisions are critical, given the "unknowns" relative to the cost and, maybe more important, in this case the length of time necessary to be effective. Therefore, it is imperative that the temporal dimensions of each strategy need to be carefully monitored due to the lack of a sound foundation of data from which the plan can be developed. The short-, medium-, and long-term time perspectives need to be assessed to help insure that the plans objects are being met.

\section{CONCLUDING THOUGHTS}

The proverbial seeds of change are at work in the Koreas today, where some form of economic unification between the centrally controlled Democratic People's Republic of Korea (North Korea) and the democratic Republic of Korea (South Korea) seems not impossible within the next 5 to 10 years. Should the political and economic environment of economically united Koreas permit entry by foreign interests, the teeming configuration of 73 million Koreans, rich businessmen and impoverished subsistence farmers all, would provide a tempting consumer base for some forms of diversified goods. Determining what goods these Koreans would want and how to earn their trust remains a key question.

Since the Koreas are presently separate and North Korea is all but completely closed to Western outsiders, a good foundation of data and information reflecting demand is immensely difficult to come by. However, based on the raw data on the combined Koreas, indeed, seems a promising emerging market with a large population, few natural resources, and hence some amount of demand for foreign goods. In order to experience any level of influence or success in a combined Korean market, Western organizations need to focus their efforts on developing strong partnerships with Chinese and Korean companies in order to work from the inside to earn Korean trust.

While joint ventures were discussed as a probable course of action earlier in this article, no form of partnership or alliance is without flaws. Joint ventures are a particularly risky mode of market entry. Despite this level of risk and the many other apparent barriers to business action in the joined Koreas, it seems that any measure of success in the potential united emerging market of North and South Korea would be dependent on some foundation of trust and acceptance. The idea of conducting business in tumultuous, united, yet politically dissimilar markets is immensely risky as well, and following through with any sort of market entry plan would demand both skill and willingness to break from accepted strategy. 
To gain insights as to how to interface with the North Korean consumer marketplace as well as the "mysterious" government agencies, the following areas for future research and policy driven activities should be considered:

- Development of joint ventures with South Korean companies: The resulting privatization of government properties and economic ventures would seem to be a logical outcome if unification is to take place (Meyer 2002). Therefore, companies that feel that the government agencies as well as certain consumer segments could provide the basis of a market opportunity should be explored using local North Korean agencies/organizations.

- Increase the level of direct foreign investment: Both the public and private sections need to identify key industrial segments as well as companies that could benefit from the infusion of capital. Public funding of infrastructure and schools would look like a potential target of opportunity to "jump-start" the economy, whereas investments in primary industries (e.g., steel, concrete, extractive industries) could improve economic options for key industrial segments.

- Development and revitalization of infrastructure keyed to trade with South Korea: Most economists would argue that developing a modernized infrastructure in North Korea would be the first step in stimulating the economy. At the same time, infrastructure tied to trade with South Korea could go a long way to normalizing relationships and trade.

- Encourage and stimulate cultural/social interactions between South and North Korea: Given the rich cultural and social tradition of cultural and social events between the two countries, these events should be rejuvenated. This would be an excellent access for NGOs to provide the sponsorship for such events.

Ultimately, the world as we know it will continue to shrink, and globalization will become an ever-more integral facet of international business. The big players of China and Japan have already leapt onto this world stage. It has happened before: Germany, in the aftermath of World War II and the fall of the Berlin wall (1989), was able to come together, assimilate dissimilar political schemes, and establish the most vibrant, successful economy in the European Union. In this light, North and South Korea have the potential to become yet another emerging economy of immense importance. In order to stay on top, the United States will need not only to react to external forces of change and globalization but preemptively adopt a proactive stance toward the changing world. By modifying existing strategies and acting quickly, building on existing partnerships and laying new foundations of cultural acceptance and trust, Americans could become viable competitors in just one more of the emerging economies of the future. It is by identifying these emerging markets, like the potentially merging Korean economies, 
before they make the headlines of BusinessWeek or The New York Times that companies will be able to reach new markets and stay ahead of the game. However, remember, "Be careful, what you wish for; it might come true!"

\section{REFERENCES}

Arrighi, G., B. Silver, and B. Brewer. 2003. Industrial convergence, globalization, and the persistence of the North-South divide. Studies in Comparative International Development 38 (1): 3-22.

Carpenter, T., and D. Bandow. 2004. The Korean conundrum: America's trouble relations with North Korea. New York: Palgrave-Macmillin.

Central Intelligence Agency. 2013. World factbook. Washington, DC: Central Intelligence Agency.

Chamberlin, P. 2004. Cultural dimensions of Korean reunification: Building a unified society. International Journal of World Peace XXI (3): 123-135.

Conforti, J. M. 1999. The China model of Korean reunification. East Asia: An International Quarterly 17 (4): 54.

Dawson, C. 2005. Emerging markets: Beyond the big four. Bloomberg Businessweek, December 26.

Ducruet, C., and J. Cheol. 2009. Coastal cities, port activities and logistic constraints in a socialist developing country: The case of North Korea. Transport Reviews 28 (1): $1-25$.

Duysters, G. 2009. Internationalization and technological catching up of emerging multinationals: A comparative case study of China's Haier group. Industrial and Corporate Change 18 (2): 325-349.

Haggard, S. 2007. Famine in North Koreas: Markets, aid and reform. New York: Columbia University Press.

Hart-Landsberg, M. 1996. Korean unification: Learning from the German experience. Journal of Contemporary Asia 26 (1): 59.

Homola, V. 2010. South Korea: Looking to Germany for lessons on reunification. New York Times, August 2.

Hwang, E. 2010. The search for a unified Korea: Political and economic implications. New York: Springer.

Kerr, D. 2005. The Sino-Russian partnership and US policy toward North Korea: From hegemony to concert in Northeast Asia. International Studies Quarterly 49 (3): 411-438.

Laney, J. 2003. How to deal with North Korea. Foreign Affairs 82:16-32.

Levin, N., and Y. Han. 2002. Sunshine in Korea: The South Korean debate over policies toward North Korea. Monograph Report MR-1555-CAPP, Rand Corporation.

Meyer, K. 2002. Management challenges in privatization acquisitions in transition economies. Journal of World Business 37 (2): 266-276.

Mitchell, D. 2002. A blueprint for U.S. policy toward a unified Korea. Washington Quarterly 26 (1): 123-137.

Moltz, J. 2004. Getting serious about a multilateral approach to North Korea. Nonproliferation Review 11 (1): 136-144. 
Napier, N. K. 2005. Knowledge transfer in Vietnam: Starts, stops and loops. Journal of Managerial Psychology 20 (7): 621-636.

Napier, N. K. 2006. Cross-cultural learning and the role of reverse knowledge flows in Vietnam. International Journal of Cross-Cultural Management 6 (1): 47-64.

Napier, N. K., and L. Nguyen. 2005. Socialism and materialism in Vietnam: Legacy for state owned enterprise payment systems. In Modernization and social transformation in Vietnam, ed. G. Murt and R. Klump, 130-143. Hamburg, Germany: Institut für Asienkunde.

Nguyen, V. T., and N. K. Napier. 2000. Work attitudes in Vietnam. Academy of Management Executive 14 (4): 142-143.

Noland, M., S. Robinson, and T. Wang. 2000. Modeling Korean unification. Journal of Comparative Economics 28 (2): 400-421.

"One Korea?" 2008. Poll. The Atlantic, January 1. http://www.theatlantic.com/ magazine/archive/2008/01/one-korea/306604/.

Park, H. 2002. North Korea: The politics of unconventional wisdom. Boulder, CO: Lynne Rienner.

Pinkston, D. A., and P. C. Saunders. 2003. Seeing North Korea clearly. Survival 45 (3): 79-102.

Prahalad, C. K. 2005. The fortune at the bottom of the pyramid: Eradicating poverty through profits. New Delhi: Pearson Education/Wharton School Publishing.

Ralston, D., T. V. Nguyen, and N. K. Napier. 1999. A comparative study of the work values of North and South Vietnamese managers. Journal of International Business Studies 30 (4): 655-672.

Rosecrance, R. 2006. Power and international relations: The rise of China and its effects. International Studies Perspectives 7 (1): 31-35.

Shambaugh, D. 2003. China and the Korean peninsula: Playing for the long-term. Washington Quarterly 26 (2): 43-56.

Smith, H. 2002. Bad, mad, sad or rational actor: Why the 'securitization' paradigm makes for poor policy analysis of North Korea. International Affairs 76 (3): 593-617.

Stares, P., and J. Wit. 2009. Preparing for sudden change in North Korea. Report No. 42. Washington DC: Council on Foreign Relations, Center for Preventive Action.

Stein, K. 2002. United States forward presence in a Unified Korea. Working Paper 31, U.S. Army War College Strategy Research Project, Carlisle, PA.

Vu, T. V., and N. K. Napier. 2000a. Paradoxes in Vietnam and the United States: Lessons learned: Part I. Human Resource Planning Journal 23 (1): 7-9.

Vu, T. V., and N. K. Napier. 2000b. Paradoxes in Vietnam and the United States: Lessons learned: Part II. Human Resource Planning Journal 23 (2): 9-10.

Vu, T. V., and N. K. Napier. 2000c. Paradoxes in Vietnam and the United States: Lessons learned: Part III. Human Resource Planning Journal 23 (3): 9-10.

Worden, R. (Ed.). 2008. North Korea: A country study. Washington, DC: Government Printing Office.

Young, S., L. Chang-Jae, and Z. Hyoung-Soo. 2000. Preparing for the economic integration of two Koreas: Policy changes to South Korea. Journal of the Peterson Institute for International Economics 251-271. 